\title{
PROMESSAS PARA A CIDADE EM TEMPO \\ DE CAMPANHA ELEITORAL
}

\section{PROMISES TO THE CITY AT ELECTORAL CAMPAIGN TIME}

\author{
Irlys Alencar F. Barreira*
}

\section{Introdução}

A palavra "promessa" exprime, na língua portuguesa, possibilidades e significados diversos de uso. 0 dicionário Aurélio exibe para o termo a seguinte definição: “declaração em que se anuncia a outrem ou a si mesmo uma ação futura, ou intenção de dar, cumprir, fazer ou dizer algo". Registra, o glossário, outro sentido de cunho religioso: "oferta ou obrigação a que alguém se compromete perante uma divindade ou santo para obtenção de uma graça” (FERREIRA HOLANDA, 2016).

A promessa, pode-se afirmar, envolve uma perspectiva relacional, supondo interação com outro, ou outros, com os quais se estabelece um enunciado alusivo a ações futuras. Na condição de anúncio de um cumprimento, ela permite, com efeito, a modulação de conflitos, suscitando potenciais formas de sociabilidade (MORAES FILHO, 1983).

No ambiente mais específico da política brasileira, seria possível acrescentar, à análise de Simmel, que a promessa exprime uma condição agonística de crença e suspeita. Quando falada por políticos, a palavra vem perdendo credibilidade, pela distância, quase frequente, entre o discurso e a ação correspondente. Entretanto, não é possível pensar em candidaturas a cargos de representação sem a projeção positiva de feitos que cada postulante imagina para sua gestão, na hipótese de ser eleito. Em tais circunstâncias, a promessa faz parte do elenco das intenções de candidatos, integrando o que se chama comumente de programa de campanha.

Interessa, sobretudo, neste artigo, pensar na formulação da promessa, seja de modo explícito ou denegado, ocupando um lugar

\footnotetext{
* Doutora em sociologia e Professora Titular de sociologia, Programa de Pós-graduação em Sociologia e Departamento de Ciências Sociais, da Universidade Federal do Ceará (UFC/Fortaleza/CE/BR). ialencar21@ uol.com.br.
} 
significativo no discurso político, notadamente em eleições municipais. A proposta analítica não é verificar a credibilidade da promessa na política. Tampouco avaliar a distância entre "intenção e gesto" de candidatos em disputa eleitoral.

Inicialmente, é importante ressaltar que nos pleitos eleitorais emergem representações e disputas simbólicas baseadas em projeções sobre a cidade, ao lado de críticas usualmente feitas por setores profissionais, entidades populares, ou populações, de modo geral, amparadas nas noções de direitos urbanos e cidadania, contra formas personalizadas de exercício do poder.

Muito embora os discursos alusivos a ações futuras persistam com vigor, é possível detectar mudanças de forma e maneiras de explicitação, suscitando a ideia de que "não se fazem promessas como antes". Desse modo, esforços de construção de veracidade do prometido, com amparo jurídico, ou exigências de cumprimento, direcionando uma possibilidade prática de cobrança, vêm ampliando significados e deslocamentos de sentidos. A tentativa de equivalência entre promessa, programa, proposta e projeto, de modo a retirar da primeira a condição de incerteza, baseia-se na busca de uma obrigatoriedade de efetivação. $0 b$ servam-se, portanto, inúmeras possibilidades de uso ou apropriação da promessa no discurso político, tornando-a um símbolo passível de muitos manejos.
Os aportes teóricos que embasam este escrito coadunam-se com a ideia de que as ações políticas e seus domínios simbólicos encontram-se articulados a várias atividades da vida social, não se restringindo a um lugar específico de atuação, tal como ocorre em sua formulação estatal. 0 modo como as representações sobre a política são vividas, interpretadas e relacionadas a práticas sociais ampara-se na reflexão elaborada no âmbito da rede de investigadores conectados em torno do $\mathrm{NuAP}^{1}$. A antropologia da política, em uma perspectiva compreensiva sobre os acontecimentos cotidianos que envolvem relações de poder, trata o modo como os atores sociais interagem e atribuem significado à política; pressupõe a necessidade de investigá-la com base em pontos de vista nativos, para além da institucionalidade e circunscrita ao cotidiano da população ${ }^{2}$.

Ao longo de pesquisas anteriormente realizadas, seguindo a inspiração do $\mathrm{NuAP}$, venho refletindo sobre as possibilidades de apreensão das representações sociais, em momentos especiais, como as eleições. Baseei-me na percepção de que os rituais de campanhas eleitorais, nos quais se incluem os discursos, realçam comportamentos e valores presentes não só no campo específico da política, mas ampliando-se em outros espaços da vida social ${ }^{3}$.

No curso desse trajeto, pensar o "tempo da política"4 como um "tempo de promessas" implica verificar o acionamento de classifi-

1. Ver NuAP, site: <http://nuap.etc.br>.

2. Para uma contextualização da antropologia brasileira, em diálogo com a internacional, tendo por base uma análise enfatizando a coleção Antropologia da política, ver Peirano (2008). Outra reflexão contextualizada da mesma coleção encontra-se em Comerford e Bezerra (2013). Para uma explanação didática sobre o modo como a Antropologia da política dialoga com outra divisão no interior da disciplina nomeada antropologia política, ver Kuschnir (2007).

3. Ver Barreira (1998).

4. Para uma reflexão sobre o "tempo da política" como categoria nativa que se explicita em práticas e arranjos políticos, próprios da época eleitoral, ver Palmeira e Heredia (1995). 
cações e discursos nativos, que se interpõem na ocasião em que aspirantes a cargos de representação disputam credibilidade e bens simbólicos de reconhecimento, fundamentados no que supostamente farão por seus eleitores. 0 uso de verbo no futuro, sinalizado na frase "se eleito, farei..." é estruturante do conjunto de falas de candidatos os quais, no momento das campanhas, disputam reconhecimento pelo voto e capacidade de transformar palavras em crenças.

0 momento de campanha eleitoral é particularmente profuso de discursos sobre o espaço urbano e, não seria exagerado afırmar, que os pleitos municipais põem as cidades na "vitrine", com exposições que oferecem ao público, tanto imagens ufanistas de enaltecimento, como de crítica. As campanhas eleitorais municipais promovem o que designei em trabalho anterior de "exposição da cidade em close up" (BARREIRA, 1998) referindo-me à centralidade do espaço urbano evidenciada nos discursos e rituais próprios do "tempo da política".

Representações sobre a cidade "real" e a "cidade ideal" emergem no momento das campanhas eleitorais municipais e, como parte de um jogo político, as promessas são, também, evocações de possibilidades de mudança. Jogo no sentido de que as promessas circulam em torno de uma retórica que supõe acusações ("promessas não cumpridas"), dificuldades ("promessas de difícil cumprimento"), concorrência ("promessas em disputa”) e reiteração ("promessas adiadas”).

Tendo como material empírico principal a campanha eleitoral de candidatos à Prefeitura de Fortaleza, em 2012, acrescido de breves informações sobre a disputa de 2016 no mesmo município, observei as promessas para a cidade no discurso de candidatos, considerando o espaço urbano como local de estratégias projetivas. Projeções feitas para áreas específicas de atuação das políticas públicas (saúde, educação, segurança, infraestrutura, entre outras), além de propostas de mudança dirigidas a determinados bairros.

0 material de pesquisa ${ }^{5}$ constituiu-se de notícias de jornais (reportagens e artigos), entrevistas de candidatos concedidas aos meios de comunicação, gravação de programas televisivos, declarações, além de escuta aleatória de conversas, próprias de um momento no qual as opiniões circulavam, mesmo quando não provocadas pela pesquisadora.

Em termos amplos, considerei que as promessas constituem um conjunto de assertivas que integra o elenco das intenções dos candidatos, anunciando o que pretendem fazer pela cidade. Muito embora a palavra promessa nem sempre apareça, explicitamente, considerei que evocações similares nomeadas de compromisso, programa ou proposta eram interessantes de serem observadas, sob vários aspectos. Antes de atestarem o "desaparecimento da promessa”, apontavam tensões e dificuldades nos modos de torná-la crível, sinalizando um nexo de relações e representações importantes para compreensão de discursos políticos de campanha.

Assim, tomar as promessas como chave de leitura supõe não tratá-las de maneira substantiva, buscando apreender suas diferentes formas nativas de expressão. Refiro-me ao modo como candidatos dizem "o que farão"

5. Trata-se de pesquisa que foi apoiada pelo Edital Universal do CNPq, em 2011, realizada em parceria com a professora Danyelle Nilin Gonçalves, com o título "A cidade no discurso eleitoral”. 
em suas gestões, se eleitos; à maneira como jornalistas incitam candidatos a se declararem a respeito de suas pretensões e os demais usos da palavra promessa, seja em sua feição propositiva, acusatória ou interrogativa.

Uma abordagem das promessas, fundamentada em uma antropologia da política, implica a análise do contexto de referência no qual elas são produzidas, observando a forma como são ditas, a quem se dirigem e por quem são formuladas, em substituto à observação de supostos normativos baseados na identificação de incongruências entre o dito e o não feito ou, comparando, o que seria da ordem da demagogia ou da verdade. Nesse sentido, torna-se relevante observar as ações e os usos discursivos que gravitam em torno das promessas, feitas por candidatos, como parte de um jogo político circunscrito à própria dinâmica da competição eleitoral. Em síntese, interessam registrar as várias formas de nomeação das promessas na fala de políticos, extensivas a diferentes interlocutores, analisando os conteúdos, a quem elas se dirigem e como são articuladas no caso das eleições municipais, a "cidade real" e a "cidade prometida".

Outro ponto a destacar no modo de tratar a promessa é a de concebê-la integrada a uma rede de relações, supondo não apenas eleitores e candidatos, mas profıssionais dos meios de comunicação, formadores de opiniões e demais interlocutores que se põem, muitas vezes, na condição de avaliadores de propostas políticas. Assim, é possível canalizar as observações empíricas para um circuito de práticas, nas quais estão presentes jornalistas, instituições de política urbana, eleitores e candidatos. Estes últimos, frequentemente inquiridos, durante a campanha, a responder que soluções pretendem para várias situações consideradas problemáticas na cidade.
Uma mesma pergunta feita a todos os candidatos sobre como resolveriam os problemas da saúde, segurança, preservação do patrimônio no centro da cidade, bairros da periferia, produziu um conjunto de respostas que podem ser nomeadas de "promessas induzidas”. Demandas vindas de movimentos sociais, ou provenientes de situações inusitadas, surgidas durante as campanhas, promovem, da mesma forma, discursos de candidatos caracterizados por assertivas dotadas de soluções projetivas para a cidade. 0 fato é que, aquilo que cada candidato afirma que fará pela cidade, não constitui uma formulação fixa ou defınitiva, estando enredada em um conjunto mais amplo de falas e ações, exprimindo diversos significados e apropriações que exemplificam o caráter performático da promessa.

\section{Promessas: um ato de fala performático}

As promessas de campanha não podem ser analisadas unicamente com base nas características objetivas do discurso que as comportam, tendo em vista o fato de que instituem, no ato de fala, aquilo que proferem, sendo assim performáticas. Os discursos performáticos, na perspectiva de Austin (1990), iniciam-se com vocábulos significativos tais como aposto, dou, prometo. Essas são palavras comumente usadas para designar o ato que se segue ao pronunciamento. 0 autor analisa o grau de felicidade ou eficácia de uma declaração, ou seja, sua capacidade de exprimir um ato percebido como verdadeiro, supondo a existência de certas condições de realização daquilo que foi anunciado. A concepção de que as falas são indutoras de atos e vice-versa supõe princípios complexos referentes às condições de enunciação, às formas de proferir sentenças e à contratualidade entre falante e ouvinte. 
Apropriando-me das reflexões de Austin, posso considerar que o caráter performático do discurso político, a exemplo da promessa, tem a especificidade de uma crença cuja eficácia é processual, na medida em que só é integralmente comprovada, ou denegada, a longo prazo. A ação, alusiva a um futuro, induz uma avaliação do autor da promessa, acerca da responsabilidade da sua enunciação, o que implica um julgamento da credibilidade de quem fala. 0 fato de as promessas, do 'tempo da política', aludirem a uma realização incerta, faz com que elas, uma vez compondo o elenco das intenções de postulantes a cargos de representação, sejam inquiridas permanentemente, ou mesmo objeto de suspeita ${ }^{6}$.

A promessa como ato de fala relacionado a convenções, contratos e contextos de elaboração supõe, por outro lado, uma avaliação circunstanciada dos atores envolvidos em um espaço de disputas. A relação entre o que é dito e quem diz aponta a necessidade de pensar nas afirmações proferidas por sujeitos, tal como pensou Bourdieu (1989), em análise sobre o campo político e o estatuto discursivo dos profissionais. Observa o autor:

(...) a verdade da promessa e do prognóstico depende da veracidade e também da autoridade daquele que a pronuncia, isto é, da sua capacidade de fazer crer na sua veracidade e na sua autoridade. 0 que seria um 'discurso irresponsável' na boca de qualquer um é uma previsão razoável na boca de qualquer outro. As expressões políticas, programas, promessas, previsões ou prognósticos 'ga- nharemos as eleições' nunca são verificáveis ou falsificáveis logicamente; elas não são verdadeiras senão na medida em que aquele que as enuncia (por sua própria conta ou em nome de um grupo) é capaz de as tornar historicamente verdadeiras, fazendo-as advir na história - e isto depende ao mesmo tempo de sua aptidão para apreciar de maneira realista as probabilidades de êxito da acção destinadas a pô-las em acto e das suas capacidades para mobilizar as forças necessárias para o fazer, ao conseguir inspirar a confiança na sua própria veracidade e, portanto, nas suas probabilidades de êxito (BOURDIEU, 1989, p. 187).

As ponderações de Bourdieu são importantes para explicitar a força simbólica das palavras como fruto de um trabalho político de produção da crença que, sabe-se, é inseparável dos atores dotados de autoridade para pronunciá-las. A "verdade das promessas" encontra-se, portanto, dependente de situações e associada ao poder simbólico, envolvendo, no caso das campanhas políticas, disputas e exigências públicas para sua legitimidade (WEBER, 1999).

É nesse sentido que as condições de realização do que é prometido vêm sendo cobradas dos políticos, buscando tornar a promessa factível, baseada na demonstração da existência de recursos, ou meios de obtê-los.

0 deslize ou a tensão entre a promessa e o programa de campanha baseia-se, assim, na linha tênue que se estabelece entre o que os políticos dizem e o que efetivamente fazem e podem fazer; ou mesmo postergar, instituindo uma espécie de dívida adiada.

6. São muitos os ditos populares de domínio público alusivos à desconfiança de eleitores: "político promete tudo na época das eleições”; "promessa de político não é dívida é dúvida”. 
A pesquisa de Heredia e Palmeira (1995) ${ }^{7}$ sobre comícios no Rio Grande do Sul e no interior de Pernambuco exemplifica o caráter cumulativo de discursos alusivos a ações futuras, constituindo um "fundo comum de promessas públicas" que funciona como referência "contábil" para posteriores cobranças. As promessas feitas em comícios eram, por outro lado, incorporadas por adversários, constituindo um espaço de competição que envolvia a honra, ou o "compromisso" dos que as anunciavam em praça pública.

No caso das eleições municipais analisadas em Fortaleza, o caráter circunstancial dos discursos de campanha põe as promessas na condição de probabilidade indefınida, não obstante elas estarem circunscritas aos diagnósticos dos problemas urbanos, tornando os candidatos potenciais agenciadores de demandas. Durante as campanhas municipais observadas, os discursos de postulantes aos cargos majoritários voltaram-se, geralmente, para a cidade com seus "problemas" e as supostas dificuldades de solução a serem enfrentadas no exercício dos mandatos pretendidos.

\section{0 que e a quem se promete}

As campanhas políticas mobilizam símbolos sociais e ideológicos que se articulam em torno da construção de uma imagem de cidade. Seja na acentuação de "sua história", na perspectiva de diminuição das desigualdades, ou acenos à participação popular, as eleições municipais pesquisadas possuem a marca dos ritos de passagem. Com efeito, um "imaginário citadino de campanha" caracteriza-se por exprimir uma disputa, pelo conhecimento e domínio da cidade, acompanhada de afırmação da capacidade de administrá-la, de modo eficiente.

As campanhas politicas municipais na capital cearense têm sido indutoras de representações dos ambientes urbanos evocados em nomeações como: Fortaleza saudável; Fortaleza Bela; Fortaleza de todos; a Fortaleza que nos move; Fortaleza merece mais etc. Estes são slogans de campanhas ou designações de frentes partidárias, que revelam o modo como cada candidato imprime significações à cidade que pretende governar. Ao longo do tempo, a retórica das eleições municipais tem como suporte representações críticas nas quais são identificadas situações de violência, desigualdades de acesso a serviços públicos, ineficácia de politicas públicas e desvalorização do patrimônio.

É importante mencionar que as retóricas políticas de postulantes ao Executivo municipal - sobretudo os de oposição - são baseadas em evocações de autorias de obras e benfeitorias, atribuindo responsabilidade à administração pública pelos problemas sociais da cidade. Os candidatos atestam conhecimento da "história da cidade", acenando com reformas urbanas, intervenções pontuais e outras práticas que afırmam projeções sobre o futuro urbano. A relação entre a crítica e a promessa supõe uma análise situacional sobre a qual incide uma ação futura: "no meu governo, eu farei diferente".

De maneira geral, esses elementos integram aspectos de uma oratória apropriada conforme as posições partidárias e a existência efetiva de comunicação entre o candidato e seus potenciais eleitores. Uma situação peculiar de candidatura à reeleição aponta, por exemplo, o debate entre conti-

7. Os autores, a partir da interpretação dos discursos de palanque e suas formas de elocução analisam as acusações de cunho moral e as promessas que configuram as formas de competição eleitoral. 
nuidade e descontinuidade, intensificando retóricas de avaliação sobre a gestão municipal anterior. "Continuar as obras", no caso de candidatura à reeleição, traz implícita a ideia de que aquele que as iniciou terá maiores condições de concluí-las.

As formulações discursivas de campanha referem-se, principalmente, à dotação de equipamentos, fortalecimento de instituições e estabelecimento de prioridades nas políticas urbanas. Uma breve exposição de propostas dos candidatos mais vota$\operatorname{dos}^{8}$ nas eleições municipais de $2012^{9}$, em Fortaleza, traz elementos importantes para se pensar sobre o estatuto da promessa e suas formas de enunciação contidas em plataformas de campanha ${ }^{10}$.

\section{ROBERTO CLÁUDIO (Partido Socialista} Brasileiro - PSB) - Nascido em Fortaleza, em 1975, e formado em medicina, com PHD em saúde pública, pertence a uma família de classe média alta, dotada de capital intelectual e capital político. É neto e filho de Reitor da Universidade Federal do Ceará, descendendo de uma família de políticos que tiveram assento na Assembleia Legislativa, desde a época da Velha República. Roberto Cláudio foi deputado estadual pela primeira vez em 2006, pelo PHS (Partido Humanista da Solidariedade), atuando como vice liderança do governo Cid Gomes (PSB). Recandidatou-se pelo
PSB, tornando-se presidente da Assembleia Legislativa, no biênio 2011-2013. Candidatou-se para chefe do Executivo municipal em 2012, vencendo uma disputa acirrada com o candidato apoiado pelo PT. Recandidatou-se pelo Partido Democrático Trabalhista e reelegeu-se em 2016, para o mesmo cargo, com uma recomposição de alianças. Suas principais propostas para as eleições de 2012 foram as seguintes:

1 - Manutenção da tarifa de ônibus mais barata do Brasil;

2 - Construção de, pelo menos, 11 Unidades de Pronto Atendimento (UPA);

3 - Construção de 80 creches, com recursos da Prefeitura e mais 80 em convênio com o Governo do Estado;

4 - Criação da Secretaria de Segurança Cidadã para participar e interferir na concepção, implementação, monitoramento e avaliação das políticas de segurança pública;

5 - Criação de instrumentos que promovam a redução da quantidade de carros em circulação, por meio de rodízio de placas, cobrança de pedágio em áreas de grande concentração, entre outras;

6 - Criação da Secretaria Municipal de Habitação e Fortalecimento da Fundação de Desenvolvimento Habitacional de Fortaleza (HABITAFOR);

7 - Promoção de 40 mil melhorias habitacionais, assim como construir, no mínimo, 20

8. Os candidatos menos votados foram Francisco das Chagas Gonzaga (Partido Socialista dos Trabalhadores Unificado, PSTU), Antônio Valdeci Cunha (PRTB) e André Ramos da Silva (PPL).

9. Trata-se de eleições marcadas por grande competitividade, após dois mandatos consecutivos da Prefeita Luizianne Lins, pelo Partido dos Trabalhadores. A avaliação da prefeita, não obstante apresentar desgaste, sobretudo entre as classes médias, era considerada positiva entre setores populares, o que implicou transferência de votos para o candidato Elmano Freitas, do mesmo partido.

10. Como fonte de pesquisa investiguei os periódicos de maior difusão em Fortaleza, assim como entrevistas e sites de campanha utilizados nas várias candidaturas. Ver jornal Diário do Nordeste. Politica. De 09 set. 2012 e 24 set. 2012; Entrevista TV Ceará, de 21 set. 2012; jornal 0 povo. Politica, de 14 set. 2012; Site: <http://G1.globo/Ceará/eleições>. Acesso em: 08 out. 2016. 
mil novas unidades habitacionais em parceria com o Governo do Estado, com o Governo Federal e as associações comunitárias reduzindo o déficit em 25\% e eliminando em 100\% as áreas de risco de Fortaleza (http:// g1.globo/Ceará/eleições).

ELMANO FREITAS (Partido dos Trabalhadores, PT) - Advogado nascido em Baturité, em 1970, é filho de agricultor e professora aposentada. Elmano construiu seu capital político participando de espaços de organização, sob influência da Igreja Católica, filiando-se posteriormente ao PT. Foi Secretário Municipal de Educação, no período 2009-2012, durante a gestão da prefeita Luizianne Lins (PT). Posicionouse, nas eleições de 2012, como o candidato aliado aos movimentos sociais e bairros populares, sendo vencedor no primeiro turno, ao lado do candidato concorrente Roberto Cláudio. Perdedor na disputa municipal, elegeu-se deputado estadual, em 2014.

Suas principais propostas para as eleições municipais de 2012 foram as seguintes:

1 - Abertura de todos os postos de saúde, durante os três turnos, além de deixar à disposição da população metade dos equipamentos, à noite, nos finais de semana;

2 - Criação de agência de desenvolvimento estratégico para oferta de 50 mil empregos para jovens;

3 - Duplicação do número de creches, passando de 139 unidades para 278;

4 - Beneficiamento de 20 mil famílias no Programa Casa Bela para quem precisa reformar sua casa, bem como realizar $30 \mathrm{mil}$ regularizações fundiárias garantindo o papel da casa;

5 - Construção de 10 mil habitações populares (http://g1.globo/Ceará/eleições).
MORONI TORGAN (Democratas, DEM) Nascido em Porto Alegre, em 1956, o candidato é oriundo de família pertencente à classe média, sendo conhecido como praticante da religião dos mórmons. Foi delegado da Policia Federal, notabilizando seu capital simbólico como "defensor intransigente” da segurança pública. Exerceu a função de Secretário de Segurança no Governo Tasso Jereissati (PSDB), em 1988, tornando-se posteriormente vice-governador, no período de 1995-1998. Foi deputado federal por três legislaturas, candidatando-se à prefeitura nas eleições de 2000, 2004, 2008 e 2012. Havendo perdido as eleições municipais de 2012, no primeiro turno, foi eleito como vice-prefeito, em 2016, na chapa de Roberto Cláudio.

Na disputa eleitoral de 2012, as principais propostas de Moroni Torgan foram as seguintes:

1 - Implantação de guarda comunitária com a instalação de vigilância eletrônica;

2 - Criação de clínicas de atendimento e especialidade médica;

3 - Centros de segurança com o monitoramento de dois guardas;

4 - Instalação de vigilância eletrônica na cidade; 5 - Apoio a movimentos de combate à droga e criação de escola em tempo integral. (http://g1.globo/Ceará/eleições).

HEITOR FERRER (Partido Democrata Trabalhista - PDT)- Nascido em Lavras da Mangabeira, em 1955, é médico com pósgraduação em doenças tropicais e saúde pública, havendo atuado na Rede Pública estadual e municipal. Foi vereador em 1988, sendo reeleito na sequência por mais três mandatos. Em 2003, teve seu primeiro mandato de deputado estadual, sendo reeleito, em 2010, pela terceira vez. Como can- 
didato a prefeito nas eleições de 2012, suas propostas foram as seguintes:

1 - Construção e manutenção de outro Instituto José Frota (IJF-2);

2 - Criação de uma Secretaria Municipal de Segurança;

3 - Construção de viadutos, alargamento de avenidas, grandes corredores em sentido único para melhorar a mobilidade;

4 - Implantação de escola de qualidade em tempo integral. Articulação com Governo Federal para obter bolsa de estudo;

5 - Criação do programa Centro de Saúde, funcionado dia e noite com unidades de atendimento rápido;

6 - Redesenho do Instituto de Planejamento da Prefeitura de Fortaleza para que se torne excelência urbanística;

7 - Plano de iluminação da cidade;

8 - Criação do programa cidade ecológica (http://g1.globo/Ceará/eleições).

RENATO ROSENO (Partido Socialismo e Liberdade - PSOL) - É advogado e servidor público, havendo constituído seu capital político desde sua atuação no movimento estudantil, no Diretório Central dos Estudantes - DCE, da UFC. Foi assessor parlamentar do deputado pelo PT, João Alfredo, posicionando-se como defensor dos direitos humanos, especificamente da criança e do adolescente. Em 2005, deixou o PT e filiou-se ao PSOL, concorrendo ao governo do Estado, nas eleições de 2006. Foi candidato a prefeito nas eleições de 2008. Suas principais propostas para as eleições de 2012 foram as seguintes:

1 - Fortalecimento de políticas de juventude, promovendo acesso à tecnologia, esporte e cultura;

2 - Segurança como fruto de promoção de justiça e direitos. Planos de segurança huma- na em parceria com bairros;

3 - Criação de Secretaria da Mobilidade com valorização do transporte público;

4 - Valorização dos profissionais de educação, ampliação de creches, universalização das matrículas de crianças de 4 a 5 anos;

5 - Gestão, democratização e promoção da saúde. Estratégias de saneamento e segurança alimentar com estimulo à produção de alimentos;

6 - Ampliação do saneamento em comunidades;

7 - Ampliação de iluminação pública, auditoria par verificar a arrecadação de luz;

8 - Elaboração de plano municipal de resíduos sólidos, discriminação de lixo através de programas de educação ambiental (http://g1. globo/Ceará/eleições).

INACIO ARRUDA (Partido Comunista do Brasil - PC do B) - É funcionário público, nascido em 1957, em Lavras de Mangabeira. Iniciou a vida política como presidente da Associação dos moradores, do bairro Dias Macedo, em 1980, tornando-se, posteriormente, presidente da Federação de Bairros e Favelas, entidade sob hegemonia do PCdo B. Foi eleito vereador em 1988. Em 1990, elegeu-se deputado estadual; em 1994, elegeuse deputado federal, sendo reeleito em 1998 e 2002. Em 2006, tornou-se senador. Disputou a prefeitura em 1996, 2000 e 2004, e, em 2012, recandidatou-se à chefia do Executivo Municipal, tendo como principais propostas:

1 - Implementação de programas de prevenção, recuperação de jovens vítimas de crack; 2 - Fortalecimento da guarda municipal;

3 - Construção de 3 novos terminais de ônibus para a integração com as linhas da RMF; 4 - Construção de 80 creches e recuperação das já existentes, criação de escola de formação continuada, ampliação da integração fa- 
mília, escola comunidade;

5 - Implantação de 18 unidades de atendimento à saúde, UPAs, criação de seis policlínicas distribuídas nas seis regionais, restauração de hospitais de emergência, transformação do hospital da mulher em hospital da mulher e da criança;

6 - Criação do Conselho Municipal de Desenvolvimento Urbano; participação da população no plano diretor através do Conselho;

7 - Transparência no orçamento; criação de coordenação extraordinária de captação de recursos e Polo Tecnológico de Fortaleza;

8 - Iluminação pública nas principais vias de transito, garantindo a segurança e valorizando monumentos, prédios e paisagens;

9 - Ampliação do sistema de limpeza urbana, valorização de campanhas educativas (http://g1.globo/Ceará/eleições).

MARCOS CALS (Partido da Social Democracia Brasileira - PSDB) - Nasceu em Recife, em 1964, é formado em sociologia. Pertence a tradicional família de políticos cearenses, sendo filho do ex-ministro de Minas e Energia, César Cals de Oliveira, que foi governador do Ceará e senador da República. É também irmão de César Cals Neto que já foi prefeito de Fortaleza. Marcos Cals se tornou deputado estadual aos 22 anos, pelo Partido Democrático Social - PDS, reelegendo-se por seis mandatos. Em 2007, foi Secretário de Justiça e Cidadania, no governo de Cid Gomes; e em 2010, candidatou-se ao governo do Estado, obtendo o segundo lugar na disputa.

As principais propostas de Marcos Cals para as eleições municipais de 2012 foram as seguintes:
1 - Melhoria da segurança com parceria e valorização da guarda municipal;

2 - Projeto de integração ônibus e metrô através de bilhete único;

3 - Implantação do projeto escola no bairro, com participação das famílias;

4 - Ampliação do Programa Saúde da Família;

5 - Plano diretor com preservação do meio ambiente a oferta de moradias;

6 - Fortalecimento do orçamento participativo;

7 - Projeto integrado de políticas públicas;

8 - Incremento do projeto de saneamento básico (http://g1.globo/Ceará/eleições).

Observa-se nas diferentes plataformas de campanha a recorrência de itens referentes a saúde, educação, moradia, transporte e desemprego, associados a proposições variadas de intervenção. As intenções anunciadas não são casuais. Fortaleza, na condição de metrópole, com um déficit de infraestrutura relativo a bens fundamentais de consumo coletivo, apresenta problemas que demandam propostas amplas, visando soluções gerais. Em tal perspectiva, observa-se uma relativa uniformização de discursos direcionados à categoria de cidadãos. Do ponto de vista dos candidatos, posicionar-se como representante de um coletivo punha as promessas na condição de um requisito que beneficiaria a todos na condição de cidadãos.

Os gráficos ${ }^{11}$, a seguir, apresentam as palavras mais repetidas pelos candidatos que obtiveram maior votação no primeiro turno, disputando as eleições em uma segunda etapa.

11. Para obtenção do gráfico, foi utilizado sistema operacional Nvivo que registrou palavras mais repetidas pelos dois candidatos, vitoriosos no primeiro turno, em 2012: Roberto Cláudio (PSB) e Elmano Freitas (PT). As palavras foram obtidas em discursos dos candidatos pronunciados em depoimentos públicos, debates e entrevistas editadas em jornais e programas televisivos. 


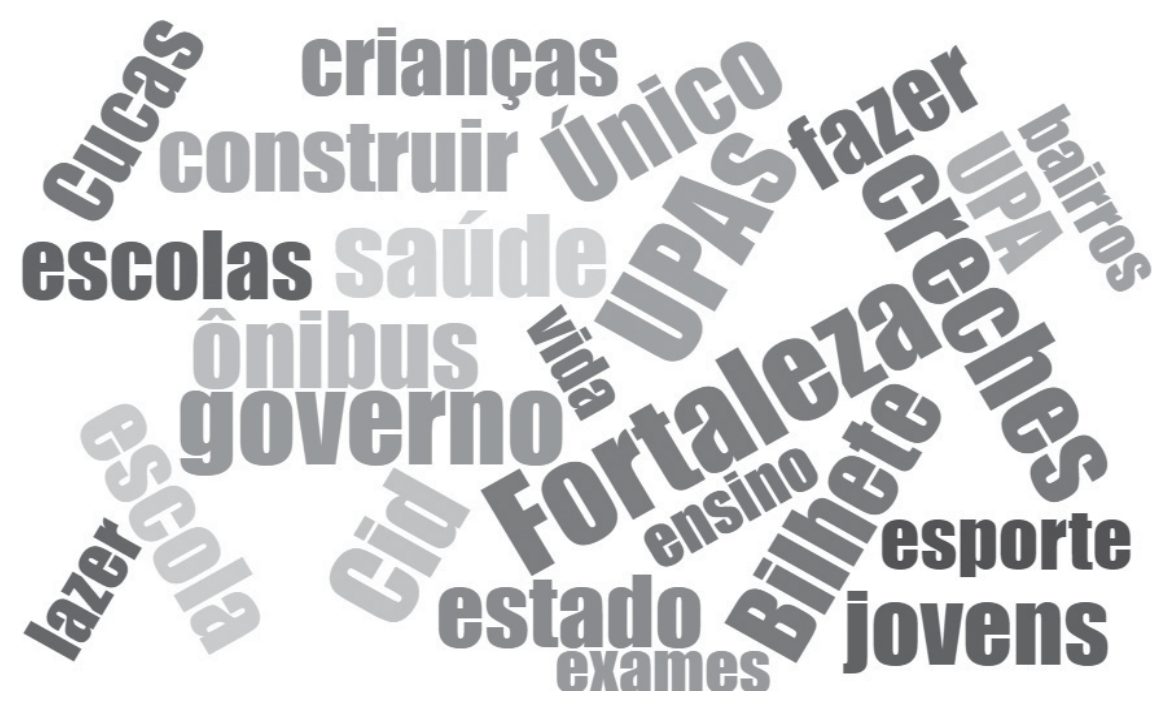

Figura 2 - Candidato Elmano Freitas (Partido dos Trabalhadores - PT)

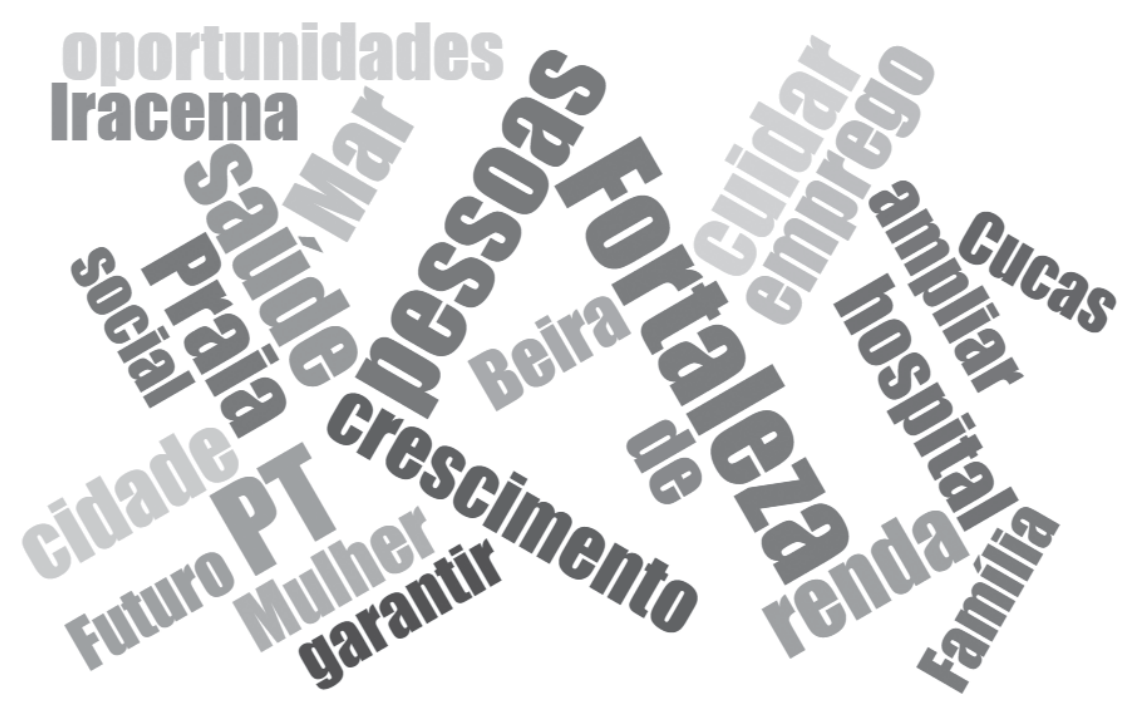


Observa-se, no gráfico, uma recorrência de palavras que se referem a lugares, pessoas e instituições, nucleadas em torno de propostas referentes a saúde, educação e moradia, transporte e geração de renda. Destacam-se, na proposta de Roberto Cláudio, as palavras jovens e lazer, muito presentes em sua campanha, a serem materializadas na criação de ciclovias e áreas de lazer. Em contraponto, na proposta de Elmano Freitas, cuja relação com moradores de periferia teve maior realce, registra-se a ideia de ampliação de oportunidades de emprego e renda, evocando garantia de oportunidades. As palavras e as propostas encontram-se associadas ao capital político de candidatos que se apresentam como mais aptos a realizações, seja por conta das trajetórias políticas, da formação profissional ou das formas de inserção entre setores populares.

Na campanha de 2016, o quadro de promessas apresentou especificidades. 0 prefeito Roberto Cláudio, candidato à reeleição, teve como principal opositor o capitão Wagner (Partido da República - PR), cujo principal emblema de campanha foi a defesa da segurança pública. A escolha de Moroni Torgan (DEM) para vice-prefeito, na chapa de Roberto Cláudio, teve por objetivo ampliar a credibilidade eleitoral, sobretudo na periferia da cidade. 0 candidato a vice, bastante conhecido entre setores populares por haver sido candidato em eleições anteriores portando o emblema da segurança, impediria também que o opositor de Roberto Cláudio, Capitão Wagner, com capital político entre os policiais militares e setores populares detivesse o monopólio do discurso contra a violência.

Tanto nas eleições de 2012, como nas de 2016, os diferentes discursos de campa- nha fundamentaram-se, principalmente, na identificação de "problemas urbanos", reportando-se a grandes áreas como saúde, educação, moradia e segurança. Ressaltase, também, a maneira como certas proposições foram numericamente enunciadas, além de ampliadas, de modo a beneficiar amplos setores da população. Destacaramse formulações relativas a princípios já previstos na Constituição, tais como direitos sociais, ecológicos e patrimoniais, não dependentes exclusivamente de políticas urbanas municipais.

Em termos gerais, é possível dizer que em ambas as campanhas emergiram duas formas de apresentar a cidade, variáveis segundo a posição política ocupada pelos pretendentes à chefia do Executivo. 0 lugar de oposição viabilizava, frequentemente, um discurso no qual os efeitos negativos de uma administração passada, considerada "ineficaz", eram mostrados através de exemplos.

Danificação de ruas, ausência de escolas, deficiência de atendimento hospitalar eram mostrados em programas televisivos, e pessoas eram indagadas a respeito da situação de seus bairros, por meio de perguntas sobre acontecimentos capazes de apontar a "incompetência da gestão municipal". Os interrogados escolhidos atuavam como espécie de testemunhas "autênticas" de uma situação vivenciada. Situações eram apresentadas nas propagandas televisivas, por meio de imagens, acompanhadas de depoimentos de moradores em condição de precariedade econômica e social. A visibilidade das carências sociais, mostrada em depoimentos e imagens, funcionava como espécie de denúncia, sendo parte integrante da retórica eleitoral em seu conjunto ${ }^{12}$. 
Embora parte significativa das promessas de candidatos buscasse manter uma interlocução direta com potenciais eleitores, o ponto básico de comunicação dirigia-se a todos os citadinos, afirmando uma espécie de "compromisso com a cidade", tal como se costuma dizer na linguagem nativa de campanha.

Por outro lado, visitas feitas a bairros populares, ou localidades consideradas problemáticas incitavam discursos específicos alusivos a soluções pontuais. Assim, na ocasião de uma caminhada, realizada na primeira fase das eleições de 2016, seguida de comício no bairro Pirambu ${ }^{13}$, o então prefeito Roberto Cláudio em campanha para sua reeleição, "identificou a presença da lama pelas ruas do bairro", afirmando, durante o percurso, ser essa uma das maneiras de "conhecer de perto" os problemas.

As propostas foram também motivo de classificação espacial, feita pela oposição, de candidatos que "não olhavam para a periferia", ou aqueles que "só beneficiavam a classe média”. Era, sobretudo, durante eventos realizados em bairros populares que as alusões a futuros feitos adquiriam um caráter de espacialidade, assumindo as carências do local como objeto de um programa de intervenção. 0 conhecimento, "de perto", dos problemas de localidades visitadas criava a expectativa de solução e afırmação de compromisso. Muito embora não houvesse distinção radical entre os discursos de candidatos, no que se referia às promessas para a cidade, os investimentos feitos por Luizianne Lins (PT) à época de sua gestão como prefeita em bairros populares (2004-2007 e 2008-2011) contabilizou capital simbólico para seu partido fundamentando a referida classificação.

Em discurso dirigido à população do bairro, o Prefeito postulante à reeleição, em 2016, fez alusão particular às mulheres, afirmando que em quatro anos pretendia construir 160 creches e 48 escolas, funcionando em tempo integral (www.policacomk.com.br). As promessas feitas de modo mais restrito aos bairros populares reiteravam a percepção do ambiente urbano em sua diversidade.

É importante ressaltar que os denominados bairros periféricos - designação menos associada a lugares e mais referenciada nas condições econômicas de moradores - são postos em contraponto aos bairros situados na zona leste da cidade, caracterizados pela presença de moradia de classes médias e altas. Não por acaso, é sobre a "periferia" que recai parte significativa das promessas de candidatos, sendo também motivo de acusação aos que "não olham para esse lado esquecido da cidade”. 0 candidato à reeleição em 2016, Roberto Cláudio, afırmava neste sentido: “criamos coisas novas que chegaram à periferia da cidade" (debate TV Cidade, 2016). As evocações feitas a essa zona urbana não são casuais. Acusações dirigidas, por exemplo, ao prefeito-candidato, pelo opositor Heitor Férrer (PSB), afırmando que o rival "só priorizava áreas nobres", ou "só governava para os ricos" provocaram um contra discurso baseado na menção a obras cons-

tes, uma relação de interdependência. Em campanhas eleitorais, "criticar o fato de as ruas não terem calçadas e, inversamente criticar a escassez de ruas calçadas é, por inferência, prometer ruas com calçamento”.

13. Bairro situado na zona oeste da cidade, conhecido por abrigar uma das primeiras ocupações precárias da cidade, construída, principalmente, por migrantes provenientes da seca e, posteriormente, operários da construção civil. 
truídas em bairros portadores com maior precariedade, durante o referido mandato.

Visitas diretas de todos os pretendentes, feitas a bairros populares, aconteceram desde o início da campanha, em lugares de maior afluência de moradores como feiras, ou localidades que acolhiam entidades associativas, com possiveis vínculos de apoio ${ }^{14}$.

É possivel pensar que as promessas, quando realizadas em lugares específicos e dirigidas a populações carentes, assumem a característica de "compromisso", emprestando um caráter de pacto diferente daquelas anunciadas de maneira mais geral, sendo parte de um programa de campanha.

De modo mais restrito, promessas podem dirigir-se a categorias profissionais com a mesma formação dos candidatos, ou emergirem de situações específicas como greves, perdas de direitos, ou busca de reconhecimento. Eventuais encontros entre candidatos e determinadas categorias profissionais pode, nesse sentido, assumir ares de um ritual que põe as promessas na condição de um pacto antecipado. Greves de professores, por exemplo, foram motivo de reunião com candidatos em campanhas anteriores.

$\mathrm{Na}$ medida em que as promessas passam a adquirir visibilidade e assumir um caráter público, difundido nos meios de comunicação de massa, observa-se a perda da dimensão mais personalizada que as caracterizara no passado. Não tanto sendo dirigida a eleitores, em particular, mas a cidadãos, de forma genérica a referência aos benefícios instituía uma situação de cumprimento possível de ser adiada, justificando-se o motivo por conta das dificuldades apresentadas para sua efetivação. Desse modo, projetos inconclusos, como foi o caso do discurso do prefeito-candidato, em sua tentativa de reeleição, eram justificados por conta da demora dos repasses do Governo Federal.

A promessa também pode implicar algo a ser postergado, que se refaz permanentemente, sem se cumprir por completo, tal como observou Borges (2003), em estudo sobre o espaço Recanto das Emas (Brasília). A frase proferida por políticos e candidatos - "voltarei sempre para inaugurar o asfalto" - evocava um trabalho de Sísifo, estando circunscrita a um quadro amplo de ações que implicava a relação entre pessoas individuais e representantes políticos, envolvidos em torno de "ruas por asfaltar". Em tais circunstâncias, a reiteração de promessas supunha a construção de obras em diferentes lugares, associando-se modos recorrentes de reconhecimento. Se as ações não realizadas faziam parte de uma dinâmica de promessas que causava desapontamentos e insatisfações (os não contemplados no Recanto das Emas diziam que "não votariam mais em Joaquim Roriz”), deixavam, por outro lado, o sentido de um permanente vir a ser, provocando uma condição de esperança. Trata-se de pensar a obra concluída como significante de afırmação de promessas.

Foi no âmbito de grandes obras que "beneficiariam a todos" que muitas propostas de candidatos às eleições municipais em Fortaleza se basearam, buscando definir o que seria o "patrimônio de bens" para a cidade. Em uma metrópole cuja população tem acesso desigual aos bens de consumo coletivo, a melhoria do transporte público, a segurança, a saúde e a educação cons-

14. Com o slogan de "candidato da periferia”, o capitão Wagner (PR), principal opositor de Roberto Cláudio, foi hegemônico na escolha feita na zona oeste da cidade, obtendo vantagem de 11 mil votos no segundo maior colégio eleitoral, abrangendo bairros como Conjunto Esperança, Canindezinho e Siqueira. 
tituem um estoque de "necessidades urbanas" que não contempla apenas determinados segmentos especiais. Isso não exclui a existência de impasses, sempre presentes na contradição entre reformas urbanas e retirada de "ocupantes ilegais" do espaço, a exemplo do comércio ambulante, objeto recorrente de polêmica no centro da cidade. Nessa perspectiva, as promessas figuravam mais como permanência de uma situação do que como mudança, operando em sentido contrário aos boatos e temores de deslocamento de "usuários ilegais" que costumam aparecer no período eleitoral.

Condições de vulnerabilidade e/ou ilegalidade de populações residentes em áreas de risco são, portanto, indutoras de posicionamentos a respeito de intervenções, tornando os candidatos cautelosos nos pronunciamentos e eventuais garantias de solução. Os jornalistas são hábeis, nesse momento, em solicitar dos postulantes respostas sobre soluções pretendidas para situações complexas. Sobretudo aquelas que implicam na efetivação de medidas não populares.

As grandes obras constituem um dos elementos de ancoragem das promessas, promovendo uma credibilidade política que se efetiva no ato do "fazer". Mostrar a obra seria uma forma de oposição aos que "prometem, mas não cumprem”, funcionando como espécie de retórica da visibilidade.

$\mathrm{Na}$ campanha de Juracy Magalhães (PMDB) para a Prefeitura de Fortaleza, em 1996, o slogan “Juracy faz" contrapunhase aos discursos de oposição. Programas televisivos difundidos à época apresentavam um quadro denominado "Você faz" no qual diferentes pessoas apontavam as "qualidades" do ex-prefeito e novamente candidato, justificando, por esse motivo, a escolha eleitoral. As obras mais conhecidas pelo público eram aí mostradas: viadutos, hospitais, terminais de ônibus e praças. A eficácia simbólica das obras era exemplificada da seguinte forma: "para escolher o candidato, basta abrir a janela”. Assim, era por conta das obras que as promessas supostamente realizadas assumiam uma credibilidade que ia além da retórica. Obras inacabadas, concluídas e dotadas de grande visibilidade funcionavam como sinais de crédito ou descrédito, com supremacia do olhar sobre a fala, sinalizando um jeito de dizer pela comprovação.

Maurice Bloch (1975), em estudo sobre a oratória ameríndia, reflete sobre o modo como as coisas são ditas nas situações políticas. Verifica o antropólogo as diferentes expressões de formalização do discurso político, evocando oratórias indicativas de conteúdos culturais. 0 estudo realizado em Madagascar pelo autor remete à maneira de proferir um discurso político, priorizando a forma sobre o conteúdo. Com base nessa formulação e mantendo as devidas diferenças culturais, é possível pensar que as obras públicas, no caso das disputas eleitorais municipais aqui pesquisadas, atuavam como espécies de "formas discursivas", capazes de dispensar palavras.

Assim como as obras promovem legitimação política, deixá-las pela metade, ou não concluídas, retira os créditos de candidatos, gerando um desgaste de promessas. Estas vêm sendo motivo de várias discussões incrementadas por formadores de opinião no espaço público.

\section{0 desgaste das promessas}

As promessas, ao longo do tempo, vêm se tornando espécie de categoria acusatória: "o político que promete", difere daquele que faz o seu trabalho silenciosamente, sem gerar falsas expectativas. 
Frases como "o candidato que não promete, faz" utilizada à época do candidato Juraci Magalhães (PDB); ou, “ele pode até ter boas intenções, mas não vai conseguir fazer por conta da crise" (utilizada nas campanhas de 2016), indicam a desconfiança atribuída a pretendentes a cargos de representação que geralmente são acusados de "prometer mundos e fundos durante a campanha”.

As críticas pelo não cumprido, ou a procura de "provas da credibilidade" vêm emergindo como falas integrantes de campanhas eleitorais. Em programas televisivos, as promessas fundamentavam embates entre concorrentes, munindo a oposição de críticas ao "que não foi feito" na administração municipal em vigor. Muitas vezes, a acusação dirigia-se ao que "havia sido prometido e não cumprido", buscando atestar a distância entre o discurso da campanha anterior e as políticas urbanas efetivamente implantadas. As acusações a respeito de “promessas não cumpridas", dirigidas ao candidato Roberto Cláudio, bastante enfatizadas pelo concorrente, Capitão Wagner (PR), provocavam respostas com argumentos igualmente direcionados "aos que não conseguiam ver os feitos”. Trata-se nesse momento de pensar na potencialidade da promessa em sua função acusatória classificadora, no caso de candidatura de oposição ou continuidade.

$\mathrm{Na}$ pesquisa que fundamenta este artigo, o uso das palavras propostas, compromisso, programa ou projeto, em substituição ao termo promessa, encontra-se associado ao descrédito e à vontade de apontar probabilidades de materialização dos discursos. Corrobora essa formulação a tradução numérica de obras a serem construídas ou equipamentos potencialmente adquiridos, imprimindo, na especificação da quantidade, um sentido de precisão. 0 número de casas, creches, hospitais, escolas, tal como foi enunciado na fala de candidatos, durante os pleitos apresentados, suporia a existência de um cálculo baseado em recursos orçamentários.

Com efeito, reaparece, ultimamente com mais vigor, a categoria promessa mediada pela busca de critérios pragmáticos de execução referentes a uma comprovação das possibilidades efetivas de realização. O jornalista Fábio Campos, conhecido por manter uma coluna Politica no periódico $O$ Povo na qual expõe opiniões sobre políticos em campanha, em outro contexto de eleições para o Governo do estado do Ceará, criticando a "falta de compromisso dos candidatos”, afirmou: "as promessas proferidas em campanha são como um gás que se dissipa por completo logo após fechada as urnas em outubro". Na referida coluna, veiculada no jornal $O$ Povo de 7/8/2014, por ocasião das eleições para o Governo do Estado, afirmou a necessidade de estabelecer formas de vincular as gestões aos compromissos assumidos em campanha, o que os tornariam menos fantasiosos. Prosseguindo em seus argumentos indagava: "Quem, que partido, que grupo político costuma sistematizar as promessas de um candidato para confrontar com a realidade posta em prática pelo gestor?" Sugeria, assim, o jornalista, a explicitação de tarefas e metas por meio de índices a serem alcançados, com projeção de recursos.

A cobrança das promessas enfrenta igual descrença por parte de eleitores: "Só lembram da gente durante as eleições"; "a gente vota, mas não dá em nada”; "os políticos só visitam as pessoas na época das eleições e depois esquecem”.

Ainda no âmbito dos desgastes, as promessas se contrapõem ao discurso dos direitos sociais, tendo sido identificadas com 
o populismo, ou com o uso de práticas personalistas em tratos que envolvem relação entre candidatos e eleitores. A título de exemplo, os movimentos sociais urbanos em Fortaleza, atuantes no final dos anos 1980, afırmavam "não vamos acreditar em promessas, porque nós temos o direito". Os direitos de moradores baseavam-se, naquele momento, no reconhecimento da justeza das demandas de bairros carentes, contrapondo-se à construção de clientelas cunhadas em pactos eleitorais que tinham como base a existência de promessas ${ }^{15}$.

0 descrédito nas promessas promove, também, a regulação ou o controle da suspeita por meio de aparato jurídico ${ }^{16}$. Tramita na Câmara dos Deputados ${ }^{17}$ um projeto de lei complementar (PL 118/15) afırmando que os mandatários que não cumpriram ao menos 50\% daquilo que foi prometido ficarão proibidos de se candidatarem nas eleições subsequentes. Segundo o autor do projeto, o deputado Índio da Costa, do PSD do Rio de Janeiro, a medida exigiria que os candidatos "prometessem apenas o que poderiam cumprir”, exigindo mais responsabilidade e compromisso com os eleitores. A medida possui, ainda, o intuito de "resgatar a credibilidade das instituições políticas e de seus representantes”, sendo assim justificada:

0 objetivo é que se tenha um percentual mínimo para que o político, durante o mandato, execute aquilo que ele se comprometeu na campanha eleitoral. Caso ele não consiga, ele fica quatro anos proibido de uma nova candidatura. Acho que neste momento, onde muitas coisas que foram prometidas não foram cumpridas, é uma lei moralizadora e, sem dúvida nenhuma, vai ao encontro do desejo da sociedade (ww2camara.leg.br/camaranoticias/noticias502982.html).

Trata-se de um texto indutor de polêmicas, por conta das dificuldades de aplicação prática. Como acusar autores de "boa intenção” que efetivamente não puderam cumprir o prometido por conta de fatores que escaparam a sua faculdade decisória?

0 desgaste das promessas remete à discussão sobre o modo de efetivá-las no espaço público como lugar de enunciação de um jogo político.

\section{Como se fazem promessas}

As promessas, como parte do enredo eleitoral, não constituem uma situação que congrega exclusivamente um candidato e seus potenciais eleitores. Efetivamente é possível pensá-las inseridas em um jogo político, considerando o que, a quem se promete e quem pode prometer. Promessas servem para estabelecer relações de identificação e de oposição entre os agentes, supondo um uso peculiar de retórica, incluindo um contínuo debate no qual estão presentes pactos e relações que se fazem e refazem circunstancialmente.

A associação entre o que foi proposto na campanha e a profissão dos candidatos evidencia uma autoria das promessas. 0 candidato Roberto Cláudio (PSB), por exemplo, que é médico, fez projeções para saúde, enquanto o pretendente Inácio Arruda (PCdoB), na campanha pesquisada, evo-

15. Ver Barreira (1992).

16. Sobre o tema ver: http://ww2.camara.leg.br/camaranoticias/noticias502982.html

17. Trata-se de proposta que aguarda análise na Comissão de Constituição e Justiça da Câmara, estando sujeita à apreciação do Plenário. 
cava seu tempo de militante nos bairros, fato que o credenciava na condição de "conhecedor das carências populares”. Desse modo, o capital social e político dos candidatos desempenha um papel importante na formulação das promessas, suscitando uma articulação entre quem e o que se promete.

Por outro lado, é possível verificar uma disputa para evitar os monopólios de competência. 0 candidato a vice de Moroni Torgan (DEM) em 2012, Doutor Liceu Jucá, iria "arregaçar as mangas para botar a saúde de Fortaleza nos eixos”, retirando do opositor e médico, Roberto Cláudio, a condição de conhecedor mais autorizado do tema da saúde (Programa Eleitoral, 24/9, 2012).

A disputa contra monopólios de competência para anunciarem determinados tipos de promessa supunha, também, que os candidatos não restringissem suas propostas a determinadas áreas, sob o risco de serem acusados de não perceberem a cidade em sua totalidade. Nesse sentido, na campanha de 2102, o candidato Moroni Torgan, conhecido por incrementar seu capital político na área de segurança, passou a ampliar o leque de propostas, enfatizando, por exemplo, a educação, como forma de neutralizar críticas a seu discurso sobre a violência, acusado por muitos de ser monocórdio. Nas eleições de 2016, como candidato a vice de Roberto Cláudio, portou o emblema da segurança, aliando-se ao capital simbólico do médico e parceiro em sua chapa.

Se as promessas remetem ao espaço das dívidas e personalização de relações nas eleições ${ }^{18}$, envolvendo políticos e eleitores, elas podem criar, por outro lado, uma homogeneidade discursiva, nivelando falas provenientes de tendências políticas diferentes. Assim, aquilo que é projetado para a cidade, por cada candidato, adquire o caráter de resposta aos "problemas" pontuados em pesquisas de opinião, tornando as promessas um tipo de capital simbólico a ser agenciado.

A concorrência entre promessas produz, por outro lado, a ideia de pioneirismo. No rastro dessa busca de singularidade, não é raro candidatos se referirem a um possível registro de seus programas, no cartório, como forma de atestar o caráter supostamente inovador de modos de intervenção e cobrança a serem oferecidos à população. 0 registro em cartório induziria também ideia de "seriedade das promessas”. Se eleito, o mandatário deveria prestar contas, cumprir o prometido.

É importante também sinalizar a existência de uma espécie de "patrimônio de realizações”, exigindo dos candidatos declarações de que determinados feitos do passado, sobretudo aqueles que desfrutam de credibilidade pública, terão prioridade na gestão seguinte. 0 uso do transporte público é exemplar a esse respeito, tal como anuncia o jornal 0 Povo, de 25 de agosto de 2012.

A promessa de fazer com que o eleitor chegue a seu destino sem, necessariamente, ter de passar pelo terminal de ônibus ou pagar mais

18. Faria (2005), baseada em pesquisa realizada junto aos trabalhadores rurais pertencentes ao Assentamento 18 de maio, iniciado em 1995, no Estado do Rio Grande do Sul observa que promessas eram construídas também em um campo de possibilidades. No caso dos assentados, as promessas anunciadas em uma comunidade caracterizada por relações políticas personalizadas, a falta de políticas públicas era substituída pela garantia de que o candidato eleito tentaria individualmente encontrar soluções para os problemas locais. As promessas eram destinadas ao coletivo, dirigindo-se também a particulares com os quais se estabelecia um compromisso do voto. 
de uma passagem é a campeã de audiência entre os candidatos à Prefeitura de Fortaleza. Como uma ferramenta geralmente chamada de 'bilhete único', quase todos prometem ampliar a chamada 'integração temporal', criando mais combinações entre as linhas e diminuindo o tempo de viagem do passageiro.

Outro exemplo de disputa pelo monopólio de promessas, na campanha de 2012 em Fortaleza, refere-se ao Hospital da $\mathrm{Mu}-$ lher, construído durante a gestão da Prefeita Luizianne Lins (2004-2012), cuja importância da obra era fortalecida na fala de todos os candidatos. Estes reconheciam a credibilidade popular gerada pelo empreendimento, mas não queriam que ela estivesse estritamente vinculada ao candidato apoiado pela Prefeita em 2012. Por esse motivo, as promessas de candidatos opositores ao PT referiam-se à extensão e consolidação da obra, garantindo "continuidade e o bom funcionamento".

Além da concorrência entre promessas, havia ainda cobrança, por parte dos candidatos derrotados, que afirmavam a condição posterior de oposição a ser feita, com base na vigilância a respeito da realização do que havia sido prometido ${ }^{19}$ pelo representante eleito.

Existe, portanto, um estoque de promessas que com certeza será motivo de críticas nas eleições seguintes, sobretudo em se tratando da hipótese de candidatos que tentam se reeleger. A cobrança de "promessas não cumpridas", no primeiro turno das eleições de 2016, foi feita, por exemplo, pela candidata Luizianne Lins (PT), quando indagou em comício realizado no centro da cidade: "Será que vocês ainda acreditam em polí- ticos que não realizaram suas promessas e dizem que farão na próxima gestão?".

A interpelação da candidata alude ao tema do estatuto concorrencial e ambíguo da promessa, funcionando como jogo político de crenças. Goldman (2006), refletindo sobre a questão, tendo em vista a construção de uma teoria etnográfica da democracia, lança a pergunta:

0 que pode fazer com que, pleito após pleito, os mesmos eleitores sejam capazes de ouvir mais ou menos as mesmas promessas, afirmarem que não serão cumpridas, votarem nos políticos que as proferem e, após as eleições, verem confirmadas suas suspeitas de que tudo não passava de mentira? (p. 219).

Ressalta o pesquisador que uma promessa não pode ser identifıcada por características supostamente exclusivas. É o contexto, o debate e a negociação que fazem com que uma promessa seja um "compromisso", uma "mentira" ou qualquer outra coisa. No caso da construção do Centro Cultural em Ilhéus por ele pesquisado, ação anunciada e não realizada, passou a ser defınida como "promessa" e, logo depois, como "promessa não cumprida".

0 estatuto ambíguo da promessa estaria na expectativa - todos esperam que políticos façam promessas - e, ao mesmo tempo, na desconfiança. Esta era explorada pelo candidato de oposição, nas eleições de 1996, em Ilhéus, que sustentava ser um político “moderno”, que não operava através de “promessas vazias”. A afirmação era, no entanto, muitas vezes interpretada de forma negativa, como um modo de evitar assumir compromissos. 
É importante enfatizar que as promessas de campanha municipal de 2012 e 2016, em Fortaleza foram também mediadas por profissionais como arquitetos, jornalistas e gestores de políticas públicas, incidindo na elaboração de discursos voltados para o enfrentamento de questões consideradas relevantes para a cidade. Nesse sentido, o Instituto dos Arquitetos do Brasil (IAB) formulou perguntas dirigidas aos candidatos sobre a política de planejamento, a possibilidade de criação de um órgão central encarregado dessa função, as diretrizes para controle do aumento populacional urbano e o tema da mobilidade. As respostas aos temas arrolados nas questões eram bem semelhantes, não obstante aparecerem algumas variações.

As propostas referentes à mobilidade, por exemplo, partiam todas do reconhecimento das dificuldades de locomoção e do escoamento de tráfego, diferenciandose algumas soluções como construção de viadutos, vias expressas (Roberto Cláudio), valorização do transporte público (Renato Roseno) ou ciclovias (Inácio Arruda) nas campanhas pesquisadas.

As variações de propostas, antes de seguirem o circuito das promessas, articulando, mais diretamente, candidatos e eleitores, supunham a existência de um estoque de cobranças para uma "cidade com problemas", supostamente reconhecidos por todos. Na realidade, o fato de o questionamento dos arquitetos não se dirigir a um candidato, mas a todos, levava em conta "exigências urbanas a serem cumpridas", pondo para cada candidato a obrigatoriedade de execução. A problemática previamente definida rompia com a ideia mais personalizada de compromisso, pondo a gestão municipal no estatuto de uma responsabilidade coletiva.

\section{Considerações Finais}

A promessa pode funcionar como espécie de dádiva antecipada do político para os eleitores, fundamentando-se no princípio de uma crença duvidosa. A não efetivação do prometido reforça a descrença: "Eu não acredito em discurso de político".

Ao contrário da dádiva (MAUSS, 2013), a promessa supõe obrigatoriedade de cumprimento, mas como ela não é exequível, no momento em que é anunciada termina carreando o sentimento de dúvida e dívida - esta última, mais ou menos instituída de acordo com a credibilidade do candidato e o jogo de forças políticas. Tudo se passa como se a promessa atuasse como promissória, a partir da qual todos os candidatos emitem seu compromisso a ser modulado no universo das crenças e possibilidades. Se os números passam a ser explicitados nos programas, como busca de comprovação da veracidade de falas, é porque a dimensão pragmática vai tomando o lugar da fala aleatória e distanciada dos recursos que caracterizaram a promessa ao longo do tempo. E, mesmo que tais recursos efetivamente ainda não existam, o teor quantitativo com o qual é anunciado supõe a existência de um cálculo orçamentário.

As promessas, ao contrário das trocas simbólicas discutidas por Bourdieu (1994), operam em sentido contrário à lógica do silêncio. Sua enunciação é pública e, no reino da concorrência, os candidatos disputam credibilidade quando afirmam serem capazes de realizá-las, seja pelo domínio da máquina administrativa, seja pelo conhecimento que possuem da cidade, ou por terem acesso parcial aos recursos federais. 0 preço da promessa é, portanto, o preço da credibilidade. Se o candidato passa aos eleitores a ideia de que vai lutar para conseguir con- 
cretizar suas pretensões pode até justificar o adiamento de propostas. Sob esta ótica, as promessas podem ser vistas como opções e possibilidades estratégicas do que pode ser feito a curto, médio e longo prazos ${ }^{20}$.

Em se tratando de um conjunto amplo de intenções para a cidade, as promessas se repartem em muitos itens e podem adquirir o ritmo da burocracia das políticas públicas. Se a contabilidade final de cada gestão municipal supõe uma análise da realização do que foi prometido, para o gestor existe o desafio das prioridades de investimento e da visibilidade de ações, tendo em vista um capital de credibilidade proveniente de diferentes segmentos sociais.

Com certeza, futuramente as promessas serão lembradas por adversários e eleitores descontentes. É nesse espaço agonístico de anúncio de intenções, construção de credibilidade e desconfiança que a promessa se apresenta como ato ilocucionário, articulando crenças e práticas políticas.

\section{Referências}

AUSTIN, J. L. Quando dizer é fazer: palavras e ação. Porto Alegre: Artes Médicas, 1990.

BARREIRA, I. Chuva de papéis. Rio de Janeiro: Relume Dumará, 1998.

0 reverso das vitrines: conflitos urbanos e cultura política. Rio de Janeiro: Rio Fundo, 1992.

A cidade em close up: imagens e apropriações do espaço em campanha eleitoral. Sociedade e Estado, v. XIII, n.1, p.135-162,1998.

BLOCH, M. Political Language and Oratory in Traditional Society. New York: Academic Press, 1975.
BORGES, A. Tempo de Brasília: etnografando lugares-eventos da política. Rio de Janeiro: Relume Dumará, 2003.

BOURDIEU, P. O poder simbólico. Lisboa: Difel, 1989. Raisons pratiques: sur la theorie de l'action. Paris: Seuil, 1994.

COMERFORD, J.; BEZERRA, M. 0. Etnografias da política: uma apresentação da coleção Antropologia da política. Análise Social, 207, XLVIII (2), on line, p. 465- 489, 2013.

FARIA, L. Modernidade e tradição: política, promessa e voto no Movimento Sem Terra. Em Tese. Revista Eletrônica dos Pós-Graduandos em Sociologia Política da Universidade Federal de Santa Catarina (UFSC), v. 2, n. 1 (3), p. 22-35, jan/jul. 2005.

FERREIRA HOLANDA, S. B. Novo Dicionário Aurélio. Disponível em: $<$ https://dicionariodoaurelio. com>. Acesso em: 08 out. 2016.

MORAES FILHO, E. Georg Simmel. Sociologia, col. Ática, tradução de Carlos Alberto Favanelli. São Paulo: Ática, 1983.

GOLDMAN, M. Uma teoria etnográfica da democracia. In: BARREIRA, C. e PALMEIRA, M. (Orgs.). Política no Brasil: visão de antropólogos. Rio de Janeiro: Relume Dumará, 2006, p. 203-226.

KUSCHNIR, K. Antropologia da política. Rio de Janeiro: Zahar, 2007.

MARI, H. A promessa como ato de fala: suas implicações no discurso político. Geraes Revista de Comunicação Social, Belo Horizonte: FAFICH/ UFMG, v.1, p. 34-41, 1997.

MAUSS, M. Ensaio sobre a dádiva: forma e razão da troca nas sociedades arcaicas. Sociologia e Antropologia. São Paulo: Cosac Naify, 2013, p. 183-314.

20. 0 projeto recente, denominado Fortaleza 2040, realizado na gestão do prefeito Roberto Cláudio, em 2015 , teve por objetivo planejar a cidade para várias gestões, constituindo uma outra tentativa de racionalizar as propostas, retirando-lhes o caráter de uma relação entre político e eleitores e alocando benfeitorias para o âmbito das políticas públicas, a longo prazo. 
PALMEIRA, M.; e HEREDIA, B. Os comícios e as políticas de facções. Anuário Antropológico 94, Rio e Janeiro, Museu Nacional, p. 31-94,1995.

Política, facções e voto, In:

PALMEIRA, M.; GOLDMAN, M. (Orgs.) Antropologia, voto e representação política, Contracapa, Rio de Janeiro, 1996, p. 41-56.

PEIRANO, M. Brasil, otherness in contexto. In: POOLE, D. A companion to Latin American anthropology. Oxford: Blackwell publishing, 2008.

WEBER, M. Economia e Sociedade, v.1, Brasília: Editora UnB, 1999.

Sites consultados:

http//:ww2camara.leg.br/camaranoticias/noticias502982.html. Acesso em: 07 out.2016.

http//:pt.wikipedia.org/wiki/eleiçao municipal de Fortaleza em 2012. Acesso em: 08 out.2016.

http//:eleicoes.uol.com.br/2012/fortaleza-proposta-dos-candidatos. Acesso em: 10 out.2016.

http//:www.policacomk.com.br>. Acesso em: 10 out.2016.

http//:g1.globo/Ceará/eleições>. Acesso em: 08 out.2016. 
RESUMO

A proposta do artigo é analisar a formulação de promessas ocupando um lugar significativo no discurso político, notadamente nas eleições municipais em Fortaleza. As promessas de candidatos, feitas de modo explícito ou denegado, apresentam representações e disputas simbólicas baseadas em projeções sobre a cidade. Pensando o "tempo da política" como um "tempo de promessas", o artigo busca verificar o acionamento de classificações e discursos nativos que se interpõem na ocasião em que aspirantes a cargos de representação disputam credibilidade e bens simbólicos de reconhecimento, fundamentados no que supostamente farão por seus eleitores. 0 artigo explora as modificações mais recentes do estatuto da promessa, verificando seu lugar no jogo político; registra as tentativas de construção de veracidade do prometido, por meio de amparo jurídico, e as exigências para o seu cumprimento, direcionando a perspectiva prática de cobrança e a existência de outros significados, que vêm deslocando ou ampliando o sentido do ato de prometer. A tentativa de equivalência entre promessa, programa, proposta e projeto, de modo a retirar da primeira sua condição de incerteza e afirmar a obrigatoriedade de sua efetivação, constitui um dos exemplos de ampliação do sentido.

\section{PALAVRAS-CHAVE}

Promessas. Discurso. Cidade. Campanha eleitoral.

\section{ABSTRACT}

The article analyze the promises in the political discourse, especially in municipal elections in Fortaleza. The promises of candidates made explicitly or not, feature representations and symbolic disputes based on projections about the city. Thinking the "time of politics" as a "time of promises", the article seeks to verify the native speeches that stand on this moment which aspiring vie for credibility and representation of symbolic goods, based on the recognition about actions that supposedly will do for theirs electors. The article explores the latest modifications of the promisse, checking your place in the game of politics. Also the article analyze the construct of validity of the promised, through legal support, requirements for compliance, directing the practical perspective of recovery and the existence of other meanings, which have moving or expanding the sense of promise. The attempt of equivalence between promise, program, and project, so as to remove of the first his condition of uncertainty and affirm the requirement for its implementation is one of the examples of expansion of sense.

\section{KEY WORDS}

Promisses. Discourse. City. Electoral Campaign. 